\title{
A MEDICATED TOOTH-PASTE, WITH A FULL STATEMENT OF ITS COMPOSITION
}

\author{
ALEXANDER LOWY \\ School of Chemistry, University of Pittsburgh, Pittsburgh, Pennsylvania
}

I was asked, recently, to devise a formula for a medicated toothpaste that would be based on scientific principles of oral hygiene. This work necessitated a careful examination of the literature of the subject, including text-books, circulars, pamphlets, formulas, etc. Since the exact compositions of many of the widely distributed tooth pastes have not been published, considerable analytical work had to be done in order to determine the character and proportion of components in these pastes that are not mentioned in the stated formulas. The larger the number of dental pastes one examines, the more one is astonished by the serious misrepresentation of some of these preparations, by the secrecy in which various formulas are enshrouded, by the omission of essential facts from public descriptions of certain pastes, and by the false or misleading statements that are offered to foster public confidence in others. A few such preparations have recently been discussed in this JouRNaL. ${ }^{1}$

In order to present the essential and characteristic properties of a good medicated tooth paste, namely, non-decalcifying and non-caustic action, non-poisonous effect, lack of material influence on the reaction of the saliva, effective cleansing power, non-abrasiveness, pleasant odor and taste, and important endamebicidal action, I have prepared a "milled" paste having the composition indicated on the next page, where the purpose and proportion of each ingredient in the mixture are specified.

\footnotetext{
1 Taylor, Greeley, Limerick, Merritt, Stillman, Hyatt, Buckley and Carney: JournaL of Dental Research, 1919, i, p. 497; also Gies and collaborators: Ibid., i, pp. 507, 509; ii (1920), pp. 293, 299, 313, 511 .
}

THE JOURNAL OF DENTAL RESEARCH, VOL. II, No. 4 
PERCENTAGE COMPOSITION OF "F. E. I.," A MEDICATEN TOOTH PASTE

Precipitated chalk. ....... (body of paste; cleanser; antacid) . . . 58.75

Glycerine . . . . . . . . . . (vehicle) . . . . . . . . . . . . . . 28.60

Water . . . . . . . . . . . . (vehicle) . . . . . . . . . . . . . . . 5.60

Starch . . . . . . . . . . (binder) . . . . . . . . . . . . . 1.10

Soap. . . . . . . . . . . . (cleanser; alkalizer) . . . . . . . . . 5.00

Russian mineral oil . . . . . . (vehicle; lubricant) . . . . . . . . . . 0.25

Saccharin . . . . . . . . (corrective; antiseptic) . . . . . . . 0.03

Emetine hydrochloride . . . . (endamebacide) . . . . . . . . . . . . 0.0015

Thymol. . . . . . . . (stimulant and antiseptic) . . . . . . 0.015

Menthol . . . . . . . . (stimulant and antiseptic) ........ 0.03

Oil of eucalyptus ....... (stimulant and antiseptic) . . . . . . 0.11

Methyl salicylate ........ (stimulant and antiseptic) . . . . . . . 0.11

Oil of peppermint . . . . . (stimulant and antiseptic) . . . . . . 0.40

99.9965

This tooth-paste is called "F. E. I." (first eliminate infection) and is manufactured by the Preventol Laboratories, Pittsburgh, Pa. I believe it meets the requirements of oral hygiene and that it will be found to be consistently as useful as the results of preliminary tests promise for it. A clinical study of the paste is now in progress, the results of which will be reported at our earliest opportunity. Dentists are invited to prepare and test this paste for themselves; or, upon request, amounts of it sufficient for clinical investigation will be forwarded to them. 